\title{
EFFECT OF PWHT ON MICROSTRUCTURE AND CREEP PROPERTIES OF HOMOGENEOUS WELDS MADE OF HR3C STEEL
}

\author{
Jakub ŘEHOŘEK Jakub ${ }^{1,3}$, Vlastimil VODÁREK ${ }^{1}$, Zdeněk KUBOŇ², Hygreeva Kiran NAMBURI ${ }^{3}$ \\ ${ }^{1}$ VSB - Technical University of Ostrava, Ostrava, Czech Republic, EU \\ vlastimil.vodarek@vsb.cz \\ 2MATERIAL AND METALLURGICAL RESEARCH, Ltd, Ostrava, Czech Republic, EU \\ creep.lab@mmvyzkum.cz \\ ${ }^{3}$ Research Centre Rez, Husinec-Rez, Czech Republic, EU \\ jakub.rehorek@cvrez.cz
}

https://doi.org/10.37904/metal.2019.859

\begin{abstract}
There are high demands placed on ensuring the integrity when building blocks of fossil power plants with USC steam parameters. Weld joints are critical parts of fossil power units. At present, the behaviour of the new austenitic steels such as HR3C (X6CrNiNbN 25-20) is not sufficiently studied. The aim of this paper is to study the microstructure and creep behaviour of the homogeneous HR3C weld joints in two states: in the as-welded state (AW) and after the post-weld heat treatment (PWHT). The PWHT was carried out at the temperature of $1230{ }^{\circ} \mathrm{C}$ for $15 \mathrm{~min}$. Stress rupture tests were performed on the cross-weld joints of tubes $\varnothing 38 \times 6.3 \mathrm{~mm}$ at $700^{\circ} \mathrm{C}$ with times to rupture up to nearly 22,000 hours. The structural changes after long-term creep exposure were studied on longitudinal sections by various microscopic techniques.

The stress rupture test results of welds after PWHT indicate slightly better long-term creep strength when compared to the AW state. The calculated creep rupture strengths at $700{ }^{\circ} \mathrm{C} / 100,000$ hours for the base material (BM) and the homogeneous weld joints after PWHT are almost the same. The AW specimens as opposed to the PWHT specimens did not show a noticeable growth of austenitic grains in the heat-affected zone (HAZ). In specimens after PWHT the average grain size in HAZ was more than twice that of the BM.
\end{abstract}

Keywords: HR3C, PWHT, creep-resistant steel, austenitic stainless steel, homogeneous weld joint

\section{INTRODUCTION}

Reducing $\mathrm{CO}_{2}, \mathrm{NOx}$ and $\mathrm{SO} x$ is one of the main goals in building new fossil power plants [1,2]. By increasing the efficiency of the fossil power plant this goal can be achieved, mainly by increasing steam operating temperature to ultra-super critical (USC) parameters. To ensure safety in the area of USC steam parameters, must be used materials with high creep strength and good steam oxidation resistance. Therefore, HR3C grade $(25 \mathrm{Cr}-20 \mathrm{Ni}-\mathrm{Nb}-\mathrm{N})$ for superheaters and reheaters with working temperature above $600{ }^{\circ} \mathrm{C}$ is widely used. HR3C steel is modified of TP310 by the addition of strong carbide/nitride-forming elements such as nitrogen and niobium. This increases creep strength. Adding nitrogen to the interstitial positions the strength of the solid solution is increased. Dispersed distribution of $\mathrm{NbCrN}$ (Z-phase), $\mathrm{M}_{23} \mathrm{C}_{6}$ carbides and $\mathrm{Nb}$-rich carbonitrides (MX) in the matrix enhance precipitation strengthening [3-6]. Due to a high chromium content in the HR3C steel an intensive precipitation of $\sigma$-phase is to be expected during long-term exposure at temperatures in the range of $600-700{ }^{\circ} \mathrm{C}$ [7]. Heavy precipitation of this intermetallic phase can result in embrittlement of HR3C steel $[7,8]$. The creep rupture strength of HR3C steel is about $45 \%$ higher than that of TP347 at $650{ }^{\circ} \mathrm{C}[3]$. HR3C steel shows higher tensile strength than TP347HFG (18Cr-12Ni-Nb) and Super304H (18Cr-9Ni-3Cu$\mathrm{Nb}-\mathrm{N}$ ) steels [4]. The high-temperature oxidation and steam oxidation resistance of $\mathrm{HR} 3 \mathrm{C}$ steel is also better than that of conventional $18 \% \mathrm{Cr}$ steels [4]. Long-term exposure in the $600-700{ }^{\circ} \mathrm{C}$ temperature range results 
in significant microstructure evolution, which in some cases material degradation. In addition to increasing the creep resistance of HR3C steel by adding niobium and nitrogen, heat treatment also plays an important role.

The paper deals with the effect of heat treatment after welding on the results of stress rupture tests at $700{ }^{\circ} \mathrm{C}$. The results of microstructure evaluation are compared in both post-weld heat treatment (PWHT) state and aswelded state (AW). The paper also deals with the results of investigations on failure mechanisms of crosswelded samples. Austenite grain size evaluation and microhardness measurement results are also discussed in this paper. Finally, minor phases in the austenitic matrix were studied.

\section{EXPERIMENTAL PROCEDURES}

HR3C supplied as tube of $\varnothing 38 \times 6.3 \mathrm{~mm}$ was chosen as experimental material. The results of the chemical composition verification and the standardized mechanical properties of the steel investigated are shown in Table 1 and Table 2. Chemical composition measurements were performed by using HORIBA GD Profiler 2 using the GDOES method and the HORIBA EMGA-830 analyser.

Table 1 Chemical composition of the HR3C steel investigated, wt.\%

\begin{tabular}{|c|c|c|c|c|c|c|c|c|c|c|}
\hline $\mathbf{C}$ & $\mathbf{M n}$ & $\mathbf{S i}$ & $\mathbf{P}$ & $\mathbf{S}$ & $\mathbf{C r}$ & $\mathbf{N i}$ & $\mathbf{N b}$ & Mo & $\mathbf{N}$ & B \\
\hline 0.10 & 1.45 & 0.51 & 0.017 & 0.0045 & 25.80 & 20.16 & 0.55 & 0.23 & 0.28 & 0.0025 \\
\hline
\end{tabular}

Weld joints were manufactured by orbital welding using the GTAW method, heat input $Q=1600 \mathrm{~J} / \mathrm{mm}$, interpass $150^{\circ} \mathrm{C}$, three beads. Nickel-base alloy UTP A6170 Co (equivalent to Thermanit 617) was used as a filler material. Weld joints were examined in the AW state and in the state after PWHT at $1230{ }^{\circ} \mathrm{C}$ for $15 \mathrm{~min}$. Stress rupture tests were carried out on the base material and cross-weld specimens at the temperature of $700{ }^{\circ} \mathrm{C}$. Times to rupture reached up to 22,000 hours. The microstructure and failure mechanisms were studied by a combination of light microscopy and scanning electron microscopy on longitudinal sections through the creep ruptured specimens. The surface of longitudinal section was prepared by grinding with $\mathrm{SiC}$ abrasive papers of the maximum fineness \# 4000. The final polishing of the surface was done with a diamond paste with an average abrasive grain size of $1 \mu \mathrm{m}$. To reveal microstructure, specimens were etched in a solution of $100 \mathrm{ml} \mathrm{H}_{2} \mathrm{O}+100 \mathrm{ml} \mathrm{HCl}+10 \mathrm{ml} \mathrm{HNO}_{3}$ for $5-15 \mathrm{~min}$. The austenitic grain size was determined using both light microscopy and EBSD method (Oxford NordlysNano detector). The EDS technique (Oxford X-Max ${ }^{\mathrm{N} 80}$ detector) was used for identification of minor phases. The results of microstructure investigations were added by measurements of microhardness HV 0.5 in accordance with the ASTM E384.

Table 2 Standardized mechanical properties of HR3C steel after solution annealing [6]

\begin{tabular}{|c|c|c|c|}
\hline $\mathbf{R}_{\mathrm{p} 0.2 / 20^{\circ} \mathrm{C}(\mathrm{MPa})}$ & $\mathbf{R}_{\mathrm{p} 0.21700^{\circ} \mathrm{C}(\mathrm{MPa})}$ & $\mathbf{R}_{\mathrm{m}}$ (MPa) & R.A. (\%) \\
\hline 295 & 155 & $655-900$ & 30 \\
\hline
\end{tabular}

Table 3 Parameters of stress rupture tests at $700{ }^{\circ} \mathrm{C}$ and rupture locations of cross-weld specimens

\begin{tabular}{|c|c|c|c|c|c|}
\hline Specimen & State & Stress (MPa) & Time to Rupture (h) & R.A. (\%) & Rupture Location \\
\hline D1 & PWHT & 100 & 6,958 & - & HAZ \\
\hline D2 & PWHT & 90 & 15,712 & - & HAZ \\
\hline D3 & AW & 120 & 3,967 & 6.7 & HAZ \\
\hline D4 & AW & 70 & 21,557 & 11.7 & BM \\
\hline
\end{tabular}

Table 3 shows the results of stress rupture tests and rupture locations on specimens investigated in this paper. The results of experimental stress rupture tests were used for extrapolation of creep strength values for $10^{5} \mathrm{~h}$ at $700{ }^{\circ} \mathrm{C}$ by using the Seifert equation [5]: 
$\log (\sigma)=\mathrm{A}_{1}+\mathrm{A}_{2} \cdot \mathrm{P}+\mathrm{A}_{3} \cdot \mathrm{P}^{2} ; \mathrm{P}=\mathrm{T} \cdot\left[\log \left(\mathrm{t}_{\mathrm{r}}\right)+\mathrm{A}_{4}\right] \cdot 10^{-4}$

where $\sigma$ is the initial applied stress, $T$ is the test temperature, $t_{r}$ is the time to rupture, $A_{1}$ to $A_{4}$ are constants and $\mathrm{P}$ is parameter. The equation (1) was applied for the calculation of the $R_{m / 700}{ }^{\circ} \mathrm{C} / 10^{5} \mathrm{~h}$ values.

\section{RESULTS}

Figures $1 \mathrm{a})$ and $\mathbf{1 b}$ ) show the results of all stress rupture tests on cross-weld specimens performed at $700{ }^{\circ} \mathrm{C}$. The curves were calculated by using the equation (1). The full marks indicate ruptured creep specimens and empty ones show the ongoing tests.
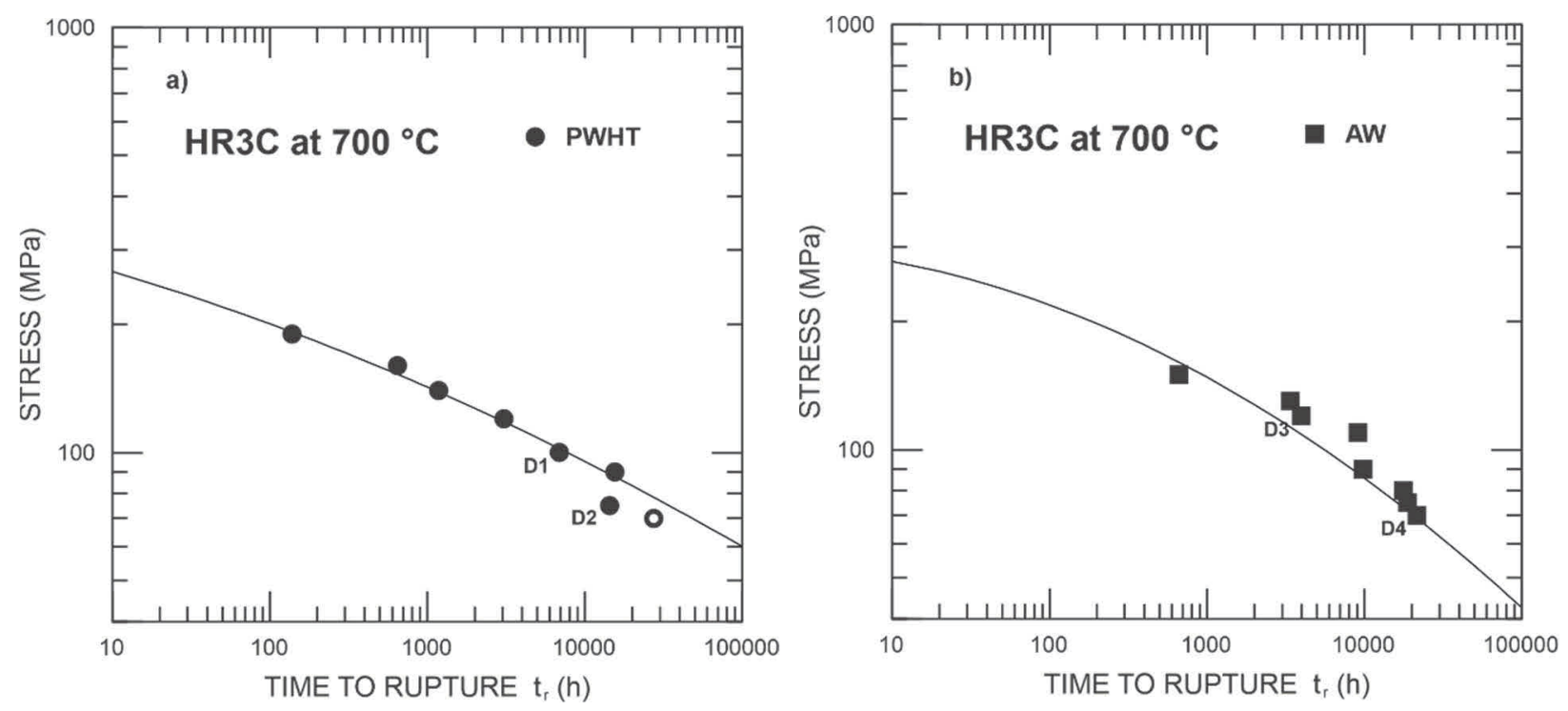

Figure 1 Results of stress rupture tests and temperature-stress dependence of time to rupture evaluated by Seifert parametric equation [5], a) PWHT state, b) AW state

Extrapolated values $R_{m} / 700^{\circ} \mathrm{C} / 10^{4} \mathrm{~h}$ and $\mathrm{R}_{\mathrm{m} / 700}{ }^{\circ} \mathrm{C} / 10^{5} \mathrm{~h}$ of the base material $(\mathrm{BM})$ and the homogenous weld joint (CW) according to the equation (1) are shown in Table 4. For comparison, the standardized values $R_{m} / 700^{\circ} \mathrm{C} / 10^{5} \mathrm{~h}$ for the HR3C steel stated in the VdTÜV Material Sheet are also shown [6].

Table 4 Extrapolated long-term creep strength values (MPa) for $10^{4}$ and $10^{5}$ hours at $700{ }^{\circ} \mathrm{C}$, according to the equation (1) for the as-welded state (AW), after the post-weld heat treatment (PWHT) and VdTÜV Material Sheet data for the HR3C steel (VdTÜV) [6].

\begin{tabular}{|c|c|c|c|c|c|c|}
\hline \multirow{2}{*}{ Location } & \multicolumn{3}{|c|}{$R_{\mathrm{m} / 700^{\circ} \mathrm{C} / 10^{4} \mathrm{~h} \text { (MPa) }}$} & \multicolumn{3}{c|}{$\mathrm{R}_{\mathrm{m} / 700^{\circ} \mathrm{C} / 10^{5} \mathrm{~h} \text { (MPa) }}$} \\
\cline { 2 - 8 } & VdTÜV & AW & PWHT & VdTÜV & AW & PWHT \\
\hline BM & 108 & 111 & 120 & 66 & 58 & 60 \\
\hline CW & - & 128 & 100 & - & 43 & 60 \\
\hline
\end{tabular}

The HAZ width if all specimens investigated (D1-D4) was approximately $1.5 \mathrm{~mm}$. The post-weld heat treatment of the homogeneous weld joint resulted in the pronounced growth of austenitic grains in the heat-affected zone (HAZ). Growth of austenitic grains in the HAZ of specimens D1 and D2 can be seen in Figure 2a) and Figure 2b), respectively. On the other hand, no evident coarsening of austenitic grains in the HAZ was observed on specimens in the AW state. Figure 2c) and Figure 2d) document microstructure in the 
specimens D3 and D4, respectively. Results of austenite grain size evaluation and microhardness measurements in individual parts of creep specimens are summarised in Table 4.

Metallographic analysis on longitudinal sections revealed creep damage along austenite grain boundaries under the fracture line, especially in the specimen D4. Cracks along austenite grain boundaries can be seen in Figures 3a) - 3d). Austenite grain boundaries were decorated by networks of minor phase particles. Cracks formed along incoherent interfaces between minor phase particles and the austenitic matrix.
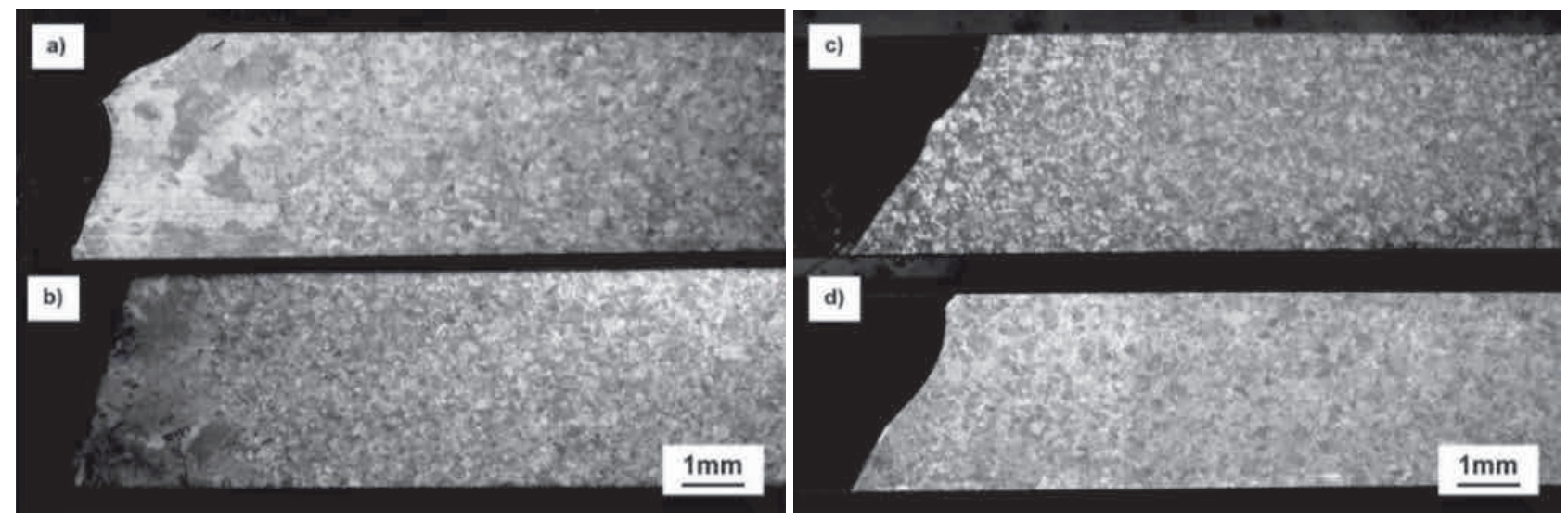

Figure 2 Macrostructure of longitudinal sections of creep ruptured specimens at $700{ }^{\circ} \mathrm{C}$, a) specimen D1, PWHT state, b) specimen D2, PWHT state, c) specimen D3, AW state, specimen D4, AW state

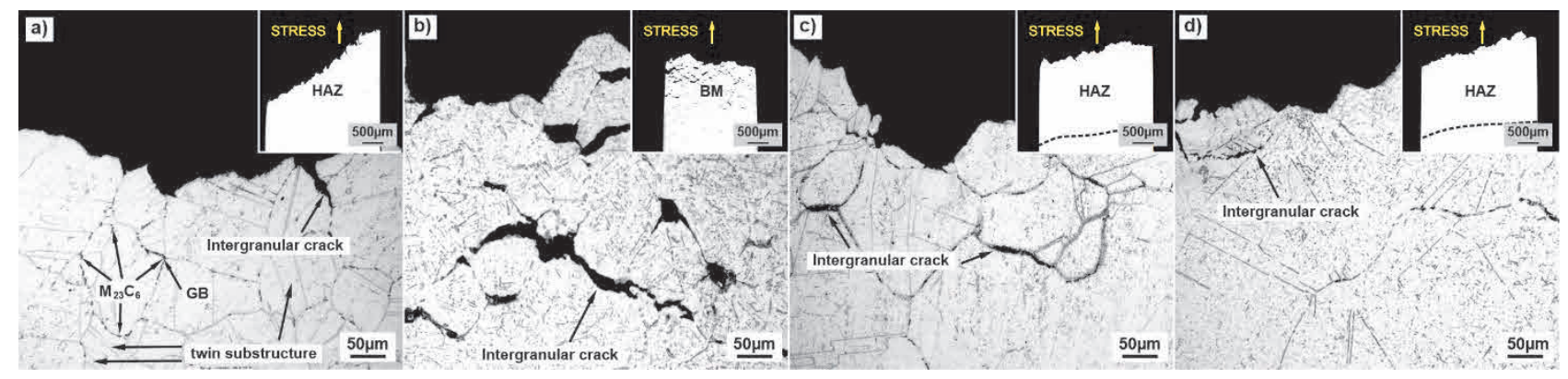

Figure 3 Defects of creep ruptured specimens under the fracture line, a) specimen D3, AW state, b) specimen D4, AW state, c) specimen D1, PWHT state, d) specimen D2, PWHT state
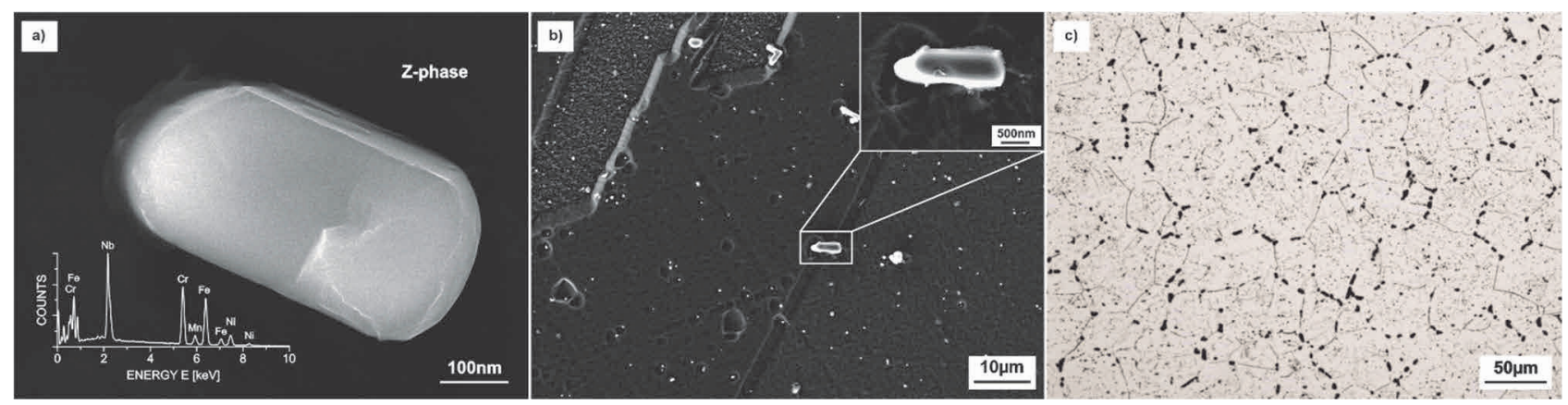

Figure 4 SEM micrograph of reference HR3C steel in the AR state, a) primary particle MX, b) primary Zphase and use LM c) $\sigma$-phase in specimen D2

Minor phases in specimens investigated were characterized by EDS in the scanning electron microscope. It was found out that particles along austenite grain boundaries were mostly formed by either $\sigma$-phase or $\mathrm{M}_{23} \mathrm{C}_{6}$ carbides. Particles along grain boundaries were coarser that those inside austenitic grains. Furthermore, in all 
specimens investigated primary MX and primary Z-phase particles were present. The Z-phase particle is shown in Figure 4a) together with an EDX spectrum from this phase. Figure 4b) shows the primary MX particle along the twin grain boundary. Significant dispersion around grain boundaries of the $\sigma$-phase in samples with a longer time to rupture is shown in Figure 4c), etched in $\mathrm{NaOH}$ solution. Using the SEM it was not possible to identify fine precipitates formed during the creep exposure. The published data indicate that fine intragranular particles in the steel HR3C are formed by $\mathrm{M}_{23} \mathrm{C}_{6}, \mathrm{Z}$-phase and MX phases [8].

Table 4 shows the average austenite grain size, as determined by light microscopy. The austenite grain size of the BM was not significantly affected by the PWHT at $1230^{\circ} \mathrm{C}$ for $15 \mathrm{~min}$. In the AW state the average austenite grain size in the HAZ was comparable with that of the BM. However, the PWHT resulted in the significant coarsening of austenite grains. The average austenite grain size in the HAZ of specimens in the PWHT state was about the double of that in the surrounding BM. Table 4 also summarises the results of microhardness HV 0.5 evaluation in specimens investigated. In all specimens no significant differences in the microhardness between the BM and the HAZ were revealed. The highest level of microhardness revealed the specimen D4 which was exposed at $700{ }^{\circ} \mathrm{C}$ for the longest time to rupture. The SEM-EBSD results on the austenite grain size were very similar to those obtained by light microscopy. Figures $\mathbf{5 a}$ ) to $\mathbf{5 d}$ ) show the typical microstructure in the BM of creep ruptured specimens. Austenite grain boundaries are decorated by networks of minor phase particles and significant precipitation is also present inside grains.

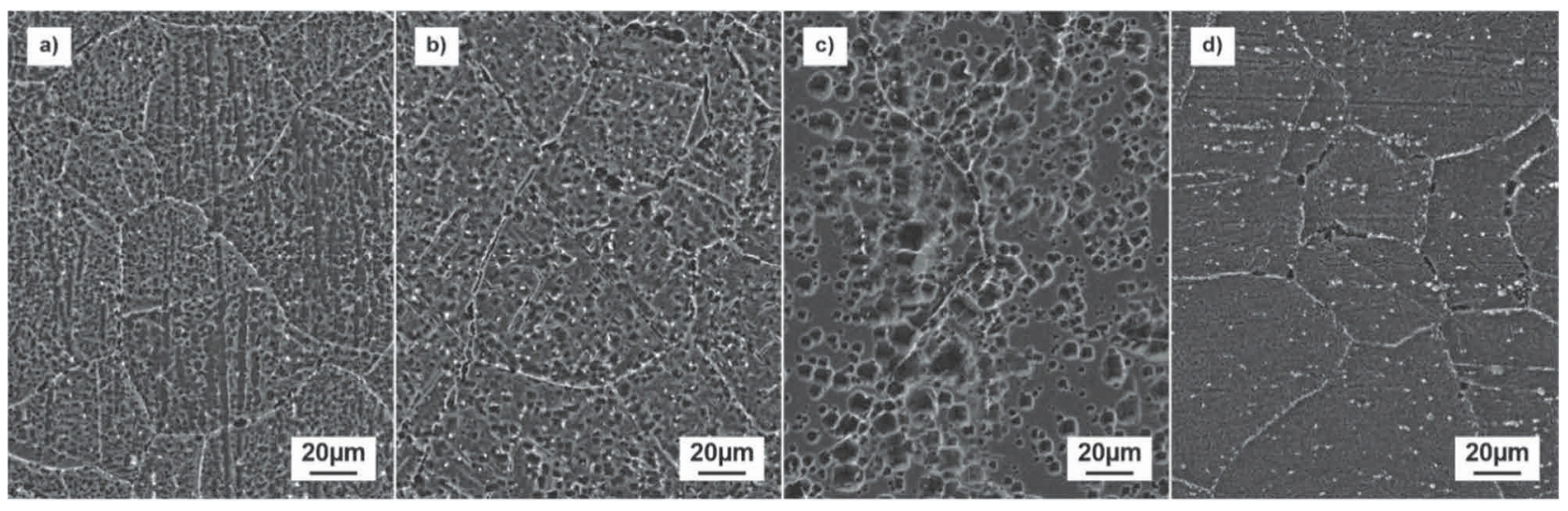

Figure 5 SEM micrographs of microstructure of the BM in creep ruptured specimens, a) specimen D1, PWHT state, b) specimen D2, PWHT state, c) specimen D3, AW state, d) specimen D4, AW state

Table 5 Average austenite grain size, as determined by LM, microhardness HV 0.5 in individual parts of cross weld specimens

\begin{tabular}{|c|c|c|c|c|c|c|c|c|c|c|c|c|c|}
\hline \multirow{2}{*}{ NO. } & \multicolumn{6}{|c|}{ Grain size $(\mu \mathrm{m})$} & \multicolumn{7}{|c|}{ Microhardness HV 0.5} \\
\hline & HEAD & BM & HAZ & HAZ & BM & HEAD & HEAD & BM & HAZ & WM & HAZ & BM & HEAD \\
\hline D1 & 98 & 86 & 227 & 248 & 93 & 85 & 233 & 236 & 235 & 275 & 230 & 231 & 237 \\
\hline D2 & 101 & 91 & 221 & 235 & 96 & 108 & 237 & 236 & 233 & 284 & 249 & 243 & 243 \\
\hline D3 & 88 & 95 & 101 & 60 & 48 & 45 & 230 & 240 & 242 & 193 & 237 & 238 & 234 \\
\hline D4 & 90 & 89 & 80 & 82 & 88 & 91 & 289 & 246 & 268 & 285 & 267 & 263 & 288 \\
\hline
\end{tabular}

\section{DISSCUSION}

Results of creep resistance evaluation of the homogeneous weld joints made of HR3C steel indicate that creep rupture strength could lie in the permissible scatter band around the standardized value. However, it has been proved that long-term exposure at $700{ }^{\circ} \mathrm{C}$ results in the pronounced precipitation of $\sigma$-phase which can result in a very low level of creep plasticity [7]. Precipitation of $\sigma$-phase seems to play a crucial role in the 
microstructure evolution. Intergranular precipitation of $\sigma$-phase is very pronounced especially in the HAZ of welds, where primary precipitates were dissolved during the thermal welding cycle. Application of the PWHT at $1230^{\circ} \mathrm{C}$ for $15 \mathrm{~min}$. resulted in the pronounced growth of austenite grains in the HAZ. It can be explained by complete dissolution of minor phases in the HAZ during the welding thermal cycle. For example, primary particles of Z-phase $(\mathrm{CrNbN})$, which are present in the $\mathrm{HR} 3 \mathrm{C}$ steel in the as-received state, can only dissolve at temperatures above $1300^{\circ} \mathrm{C}$ [7]. That is why after the $\mathrm{PWHT}$ at $1230^{\circ} \mathrm{C}$ austenite grains are much coarser in the precipitate-free HAZ than in the BM, where precipitates form obstacles for the growth of grains.

\section{CONCLUSION}

The results of investigations on the homogeneous weld joints made of $\mathrm{HR} 3 \mathrm{C}$ steel after stress rupture tests at $700^{\circ} \mathrm{C}$ can be summed up as follows:

- Weld joints in the as-welded state and after the PWHT at $1230{ }^{\circ} \mathrm{C} / 15 \mathrm{~min}$. exhibited similar creep behaviour. Extrapolated long-term creep strength values (for $10^{5} \mathrm{~h}$.) are slightly better for the PWHT state as compared to the as-welded state. Furthermore, they are very close to those for the BM. It is worth noting that creep ductility values of specimens in the state after PWHT are very low.

- $\quad$ The PWHT was accompanied by a significant growth of austenite grains in the HAZ. It can be explained by complete dissolution of minor phases during the welding thermal cycle. The following exposure at $1230^{\circ} \mathrm{C}$ for $15 \mathrm{~min}$. resulted in a fast growth of austenite grains. Coarse grained structure in the HAZ accelerated precipitation of $\sigma$-phase particles along grain boundaries during creep at $700{ }^{\circ} \mathrm{C}$ which resulted in a poor level of creep ductility. Most failures occurred in the HAZ.

- $\quad$ Coarsening of the austenite grain size in the HAZ could result in degradation of oxidation resistance and in embrittlement of weld joints.

\section{ACKNOWLEDGEMENTS}

The presented work was financially supported by the Ministry of Education, Youth and Sport Czech Republic Project LQ1603 (Research for SUSEN). This work has been realized within the SUSEN Project (established in the framework of the European Regional Development Fund (ERDF) in project CZ.1.05/2.1.00/03.0108).

\section{REFERENCES}

[1] HA, V. T. and JUNG, W. S. Creep behavior and microstructure evolution at $750{ }^{\circ} \mathrm{C}$ in a new precipitationstrengthened heat-resistant austenitic stainless steel. Materials Science and Engineering. 2012. vol. 558, pp. 103111.

[2] ABE, F. Research and Development of Heat-Resistant Materials for Advanced USC Power Plants with Steam Temperatures of $700{ }^{\circ} \mathrm{C}$ and Above. Engineering. 2015. vol. 1, no. 2, pp. 211-224.

[3] ISEDA, A., OKADA, H., SEMBA, H. and IGARASHI, M. Long term creep properties and microstructure of SUPER304H, TP347HFG and HR3C for A-USC boilers. Energy Materials. 2007. vol. 2, no. 4, pp. 199-206.

[4] LO, K.H., SHEK, C.H. and L.AI., J.K.L. Recent developments in stainless steels. Materials Science \& Engineering A. 2009. vol. 65, no. 4, pp. 39-104.

[5] SEIFERT, W. Statistische Kenngrössen aus der Ausvertung von Zeitstandversuchen. In. Warmfeste Metallische Werkstoffe 6. Zittau: Kammer der Technik, 1987, pp. 129-135.

[6] VdTÜV MATERIAL SHEET. Heat Resistant Rolling and Forged Steel X6CrNiNbN25-20 (1.4952). 2009. 5 p.

[7] VODÁREK, V. Creep behaviour and microstructural evolution in AISI $316 \mathrm{LN}+\mathrm{Nb}$ steels at $650{ }^{\circ} \mathrm{C}$. Materials Science \& Engineering A. 2011. vol. 528, no. 12, pp. 4232-4238. 